\title{
PRODUKTIFITAS KERJA DITINJAU DARI BURNOUT DAN SELF EFFICACY
}

\author{
Lukman Hakim, \\ email: kanglukmanov@gmail.com \\ Windijarto, \\ Program Pengembangan Sumberdaya Manusia \\ Sekolah Pascasarjana Universitas Airlangga Surabaya
}

\begin{abstract}
Abstrak- Suatu proses produksi dapat diketahui sebagai aktifitas yang dapat menghasilkan kegunaan (utility atau output), dan dalam menghasilkan aktifitas produksi berguna dibutuhkan input-input produksi yang tidak hanya digunakan/dinilai berdasarkan input fisik (material) saja, begitu juga dengan output yang dihasilkan dapat berupa barang maupun jasa. Faktorfaktor yang mempengaruhi produktifitas kerja karyawan antara lain tingkat burnout dan self efficacy. Populasi penelitian adalah karyawan bagian produksi di PT Semen Indonesia. Jumlah subjek penelitian adalah 300 responden. Teknik pengambilan sampel yang digunakan dalam penelitian ini adalah purposive sampling. Metode pengumpulan data yang digunakan adalah metode skala, dan analisis data menggunakan analisis regresi berganda. Hipotesis yang diajukan adalah burnout dan self efficacy mempengaruhi produktifitas kerja. Hasil analisis regresi berganda menunjukkan nilai $F_{\text {hitung }}$ sebesar $673.253>0,389$ dengan tingkat (sig) $0.000<0,05$, dan nilai signifikansi untuk uji t adalah $0,000<0,005$. hal tersebut membuktikan bahwa terdapat pengaruh yang signifikan baik secara simultan maupun parsial antara self efficacy dan burnout terhadap produktifitas kerja karyawan PT Semen Indonesia.
\end{abstract}

\section{Keyword: Produktifitas kerja, Burnout, Self efficacy}

PSIKOISLAMIKA. Jurnal Psikologi Islam (JPI) copyright @ 2016 Pusat Penelitan dan Layanan Psikologi. Volume 13 Nomor 2 Tahun 2016

\section{PENDAHULUAN}

Proses produksi di sebuah perusahaan merupakan segala aktivitas yang dapat membuat kegunaan (utility) saat ini menjadi kegunaan masa datang (Frank, 1997). Selain itu, diketahui bahwa proses produksi merupakan aktifitas yang tidak hanya membentuk barang secara material (material goods) (Ferguson, 1975). Dengan demikian, suatu proses produksi dapat diketahui sebagai aktifitas yang dapat menghasilkan kegunaan (utility atau output), dan dalam menghasilkan aktifitas produksi berguna dibutuhkan input-input produksi yang tidak hanya digunakan/dinilai berdasarkan input fisik (material) saja, begitu juga dengan output yang dihasilkan dapat berupa barang maupun jasa.

Pemahaman terhadap proses produksi akan lebih mudah dipahami pada suatu perusahaan atau industri yang berupaya mengolah input menjadi output. Perusahaan merupakan unit teknis yang mengolah komoditas, dan pengusaha (pemilik dan manajer) yang menentukan berapa besar komoditas yang akan diproduksi. Oleh karenanya, secara matematis fungsi produksi merupakan hubungan antara kombinasi input yang digunakan dalam menghasilkan output. Tujuan utama sekaligus permasalahan yang dikelola pengusaha (entrepreneur) adalah memaksimalkan profit pada kondisi tekonologi yang telah ditentukan (given).

Output atau produk yang dihasilkan perusahaan tentunya tidak lepas dari campur tangan sumber daya manusia di dalamnya. Sumber daya manusia ini akan berperan penting terhadap produk suatu perusahaan dan disebut produktivitas kerja. Produktivitas kerja adalah kemampuan menghasilkan 
suatu kerja yang lebih banyak daripada ukuran biasa yang telah umum. (The Liang Gie,1981). Produktivitas kerja merupakan salah satu factor yang sangat diperhatikan oleh perusahaan, bahkan pemecatan karyawan salah satunya karena faktor produktivitas kerja karyawan.

Produktivitas kerja ini sangat diperhatikan terutama oleh perusahaan-perusahaan besar, seperti PT. Semen Indonesia. PT. Semen Indonesia yang bergerak dalam produksi semen sangat memperhatikan kualitas produktivitas kerja karyawan-karyawannya.

Laporan KPI Transaction Departemen of Cement Production 2016 menunjukkan bahwa terdapat persoalan yang terjadi saat ini juga tentang produktivitas kerja karyawan di PT Semen Indonesia. Karyawan bagian produksi kurang memenuhi target produksi. Faktor burnout dan self efficacy diprediksi merupakan salah satu faktor yang mempengaruhi terjadinya penurunan produktifitas kerja karyawan.

Produktivitas kerja adalah kemampuan menghasilkan barang dan jasa dari berbagai sumberdaya atau faktor produksi yang digunakan untuk meningkatkan kualitas dan kuantitas pekerjaan yang dihasilkan dalam suatu perusahaan (Kusnendi, 2003., Sinungan 2005., Hasibuan, 2005). Burnout adalah suatu bentuk kelelahan yang disebabkan karena seseorang bekerja terlalu intens, berdedikasi dan berkomitmen, bekerja terlalu banyak dan terlalu lama serta memandang kebutuhan dan keinginan mereka sebagai hal kedua (Bernardin dalam Rosyid, 1996., Cherniss dalam Sutjipto, 2001., Freudenberger dalam Farber, 1991., Gehmeyr, 2000). Self efficacy adalah keyakinan khusus yang berkenaan dengan pelaksanaan suatu tugas dan melibatkan kepercayaan seseorang bahwa ia mampu untuk melakukan suatu tindakan tertentu pada suatu situasi tertentu (Bandura, 1986., Schunk, 1983).

Golembiewsky, dkk (1983) mengatakan bahwa akibat dari burnout dapat muncul dalam bentuk berkurangnya kepuasan kerja, memburuknya kinerja, dan produktivitas rendah. Apapun penyebabnya, munculnya burnout berakibat kerugian di pihak karyawan maupun organisasi. Berdasarkan penelitian Mohammad bagher Gorji tahun 2011 tentang Status Kejenuhan Kerja (Burnout) Dengan Kinerja (Job Performance) Pada Pegawai Bank menunjukkan bahwa $30,75 \%$ pegawai rata-rata mengalami kejenuhan kerja, menekankan bahwa kejenuhan kerja (Burnout) ini dirasakan oleh pegawai yang sudah bekerja antara 3 - 5 tahun.
Beberapa penelitian mengenai self efficacy terhadap kinerja juga pernah dilakukan oleh beberapa peneliti dan menunjukkan hasil yang berbeda-beda. Penelitian yang dilakukan oleh Purnomo dan Lestari (2010) menunjukkan hasil bahwa self efficacy memiliki perngaruh yang signifikan positif terhadap kinerja UKM. Selanjutnya penelitian Engko (2006) dan Chasanah (2008) menunjukkan bahwa adanya pengaruh positif self efficacy terhadap kinerja. Penelitian dengan hasil berbeda dilakukan oleh Gunawan dan Sutanto (2013) dan Prasetya dkk. (2013) menunjukkan hasil bahwa self efficacy tidak berpengaruh terhadap kinerja karyawan dan kinerja individual.

Berdasarkan uraian maka peneliti tertarik untuk meneliti pengaruh burnout dan self efficacy terhadap produktifitas kerja karyawan dengan cara mencari tahu tingkat masing-masing variabel. Hipotesis yang diajukan adalah terdapat pengaruh burnout dan self efficacy terhadap produktifitas kerja pada karyawan PT Semen Indonesia

\section{METODE}

Variabel yang digunakan dalam penelitian ini antara lain burnout dan self efficacy sebagai variabel bebas, dan produktifitas kerja sebagai variabel terikat. Subyek penelitian terdiri dari 300 responden yang menjadi karyawan bagian produksi di PT Semen Indonesia. Pengumpulan data menggunakan instrumen skala likert yang terdiri atas skala produktifitas kerja yang terdiri dari 7 aitem dan memiliki koefisien reliabilitas sebesar 0,610 , kemudian skala burnout yang terdiri dari 13 aitem dan memiliki koefisien reliabilitas sebesar 0,756 , dan skala self efficacy yang terdiri dari 5 aitem dan memiliki koefisien reliabilitas sebesar 0,560 . Teknik analisis data yang digunakan adalah analisis regresi linear berganda.

\section{HASIL}

Hasil analisis data menunjukkan bahwa ratarata karyawan PT Semen Indonesia memiliki tingkat burnout, self efficacy dan produktifitas kerja menengah sebagaimana tabel dibawah ini :

Tabel 1: Kategori Self efficacy

\begin{tabular}{cccc}
\hline Kategori & Interval & $\mathbf{F}$ & Prosentase \\
\hline Tinggi & $X>15$ & 77 & $26 \%$ \\
Sedang & $11-15$ & 173 & $58 \%$ \\
Rendah & $X<11$ & 50 & $16 \%$ \\
\hline \multicolumn{2}{c}{ Total } & 300 & $100 \%$ \\
\hline
\end{tabular}


Tabel 2: Kategori Burnout

\begin{tabular}{cccc}
\hline Kategori & Interval & $\mathbf{F}$ & Prosentase \\
\hline Tinggi & $X>41$ & 63 & $21 \%$ \\
Sedang & $30-41$ & 183 & $61 \%$ \\
Rendah & $X<30$ & 54 & $18 \%$ \\
\hline \multicolumn{2}{c}{ Total } & 300 & $100 \%$ \\
\hline
\end{tabular}

Tabel 3:Kategori Produktifitas Kerja

\begin{tabular}{cccc}
\hline Kategori & Interval & $\mathbf{F}$ & Prosentase \\
\hline Tinggi & $X>21$ & 55 & $18 \%$ \\
Sedang & $15-21$ & 204 & $68 \%$ \\
Rendah & $X<15$ & 41 & $14 \%$ \\
\hline \multicolumn{2}{c}{ Total } & $\mathbf{3 0 0}$ & $\mathbf{1 0 0 \%}$ \\
\hline
\end{tabular}

Untuk melihat hubungan antar variabel maka dilakukan analisis regresi, Hasil analisis regresi sebagai berikut,:

Tabel 4: Hasil Analisis Regresi, Pengaruh Burnout, Self efficacy terhadap Produktifitas Kerja

\begin{tabular}{|c|c|c|c|c|c|}
\hline Model & $\begin{array}{l}\text { Sum of } \\
\text { Squares }\end{array}$ & Df & $\begin{array}{l}\text { Mean } \\
\text { Square }\end{array}$ & $\mathrm{F}$ & Sig. \\
\hline $\begin{array}{c}\text { Re- } \\
\text { gression }\end{array}$ & 3254.805 & 2 & 1627.403 & 673.253 & $.000^{\mathrm{a}}$ \\
\hline Residual & 717.915 & 297 & 2.417 & & \\
\hline Total & 3972.720 & 299 & & & \\
\hline
\end{tabular}

Nilai $\mathrm{F}$ tabel pada penelitian ini adalah 0.389 untuk taraf signifikansi 0,05 . Uji F menunjukan bahwa nilai $F_{\text {hitung }}$ sebesar $673.253>0,389$ dengan tingkat (sig) $0.000<0,05$. Berdasarkan tabel diatas bahwa terdapat pengaruh self efficacy dan burnout secara simultan terhadap produktifitas kerja karyawan.

Peneliti melakukan analisa pengaruh secara parsial untuk melihat pengaruh variabel bebas berpengaruh nyata atau tidak terhadap variabel dependen. Hasil analisis menunjukkan seperti tabel di bawah ini :

Tabel 5: Analisis parsial antar variable

\begin{tabular}{|c|c|c|c|c|c|c|}
\hline & & Unstan & dardize & Standa & dize & t. sig \\
\hline & & & $S t d$ & & & \\
\hline & & B & Error & Beta & & \\
\hline 1 & (Constant) & 33.113 & 1.030 & & 32.138 & .000 \\
\hline & selfefficacy & .209 & .038 & .165 & 5.554 & .000 \\
\hline & burnout & -.481 & .018 & -.803 & -27.041 & .000 \\
\hline
\end{tabular}

Berdasarkan tabel di atas, diketahui nilai signifikansi self efficacy $0,000<0,05$ dan signifikansi burnout $0,000<0,05$. Hal tersebut menunjukkan bahwa terdapat pengaruh self efficacy dan burnout terhadap produktifitas kerja secara parsial.

\section{DISKUSI}

Hasil penelitian ini membuktikan bahwa produktifitas kerja karyawan dapat ditentukan oleh burnout karyawan, dan self efficacy karyawan itu sendiri. Hal ini menguatkan kembali pada berbagai hasil penelitian terdahulu yang menemukan bahwa semakin tinggi tingkat self efficacy, maka semakin tinggi pula produktifitas kerja pada diri seseorang. Produktifitas kerja merupakan motivasi yang terjadi pada situasi dan lingkungan kerja yang terdapat pada suatu organisasi atau lembaga. Keberhasilan dan kegagalan perusahaan memang sering dikaitkan dengan produktifitas kerja karyawan. Pada dasarnya manusia selalu menginginkan hal yang baik-baik saja, sehingga daya pendorong atau penggerak yang memotivasi semangat kerjanya tergantung dari harapan yang akan diperoleh mendatang, jika harapan itu menjadi kenyataan maka seseorang akan cenderung meningkatkan produktifitas kerjanya.

Seorang karyawan pada dasarnya memiliki produktifitas kerja yang dinamis, hal yang mempengaruhi produktifitas kerja ada banyak faktor, selain faktor burnout dan self efficacy sebetulnya masih banyak faktor-faktor lain yang ikut mempengaruhi produktifitas kerja seorang karyawan. Namun, karena keterbatasan dari penulis, penelitian ini hanya mengupas tentang pengaruh dua variabel tersebut tersebut terhadap produktifitas kerja. Burnout yang dirasakan seorang karyawan berpengaruh negatif terhadap produktifitas kerja, hal ini bermakna semakin tinggi tingkat burnout karyawan, maka semakin rendah pula produktifitas kerja yang ia miliki. Demikian pula self efficacy yang dimiliki seorang karyawan berpengaruh positif terhadap produktifitas kerja, hal ini bermakna semakin besar tingkat self efficacy yang dimiliki seorang karyawan, maka semakin besar pula produktifitas kerja yang ia miliki. Meyer dan allen (dalam meyer, dkk, 1993 ).

Hasil penelitian menunjukkan bahwa self efficacy berpengaruh signifikan terhadap produktifitas kerja karyawan PT Semen Indonesia. Self efficacy pada karyawan seperti bekerja menyelesaikan pekerjaannya tepat waktu, dapat mengatur waktu menyelesaikan pekerjaan yang ditentukan, menetapkan tujuan pekerjaan, mempersiapkan halhal terlebih dahulu dalam bekerja, selalu berusaha menyelesaikan pekerjaan, kreatif dalam berbagai hal, belajar dari masa lalu baik dari pengalaman sendiri maupun orang lain, memotivasi dirinya agar 
selalu lebih baik dan tidak mudah diserang stress. Perilaku tersebut mempunyai dampak positf dapat meningkatkan kinerja karyawan. Tanpa adanya self efficacy yang baik maka kinerja yang dimiliki karyawan kurang optimal dan akan menurun. Hal ini ditunjang oleh pernyataan Bandura (2000), bahwa pentingnya self efficacy akan berpengaruh terhadap usaha yang diperlukan dan pada akhirnya terlihat dari kinerja. Penelitian ini juga mendukung penelitian yang dilakukan oleh Nurchasanah (2008) yang menemukan bahwa self efficacy, berpengaruh terhadap kinerja karyawan.

Kepercayaan terhadap kemampuan diri, keyakinan terhadap keberhasilan yang selalu dicapai membuat seseorang bekerja lebih giat dan selalu menghasilkan yang terbaik. Menurut Philip dan Gully (1997) dalam Sapariyah (2011), self efficacy dapat dikatakan sebagai factor personal yang membedakan setiap individu dan perubahan self efficacy dapat menyebabkan terjadinya perubahan perilaku terutama dalam penyelesaian tugas dan tujuan. Penelitiannya menemukan self efficacy berhubungan positif dengan tingkat penetapan tujuan. Dengan demikian dapat dikatakan bahwa self efficacy dapat berpengaruh terhadap kinerja karyawan.

Meta analisis yang dilakukan oleh Judge dan Bono (2001) dalam Engko (2006) menemukan ada hubungan positif antara self efficacy dan kinerja individual. Penelitian yang dilakukan oleh Erez dan Judge (2001) dalam Engko (2006) juga menyatakan ada hubungan yang positif dan signifikan antara self efficacy dan kinerja individual. Hasil penelitian yang dilakukan Sapariyah (2011) menunjukkan self efficacy memiliki pengaruh yang signifikan terhadap kinerja karyawan. Pada penelitian yang dilakukan Engko (2006) menunjukkan adanya hubungan positif antara self efficacy dengan kinerja individual.

Pada penelitian ini menunjukkan hasil bahwa ada pengaruh self efficacy terhadap produktifitas kerja karyawan secara signifikan. Artinya bahwa semakin tinggi tingkat self efficacy karyawan maka semakin tinggi pula tingkat produktifitas kerjanya.

Penelitian ini juga memperkuat apa yang telah disampaikan oleh beberapa ahli dan hasil penelitian sebelumnya, diantaranya Sahak (2014) serta Maulidia \& Dhania (2011) yang menyebutkan adanya hubungan positif antara self efficacy dan produktifitas kerja.

Lain halnya dengan pengaruh burnout terhadap produktifitas kerja karyawan pada penelitian ini. Hasil penelitian menunjukkan bahwa ada pengaruh negatif burnout terhadap produktifitas kerja karyawan.

Schultz (1994) mengemukakan, seringkali burnout diderita oleh karyawan yang mempunyai dedikasi dan komitmen yang tinggi terhadap pekerjaannya. Schaufelli dan Buunk (1996) mengatakan bahwa burnout berkembang ketika individu sangat percaya bayangan ideal mereka, bahwa mereka adalah orang yang kharismatik, dinamis, tidak bisa lelah dan sangat kompeten. Hal itu mengakibatkan mereka berusaha mempertahankan kesan idealnya dengan menggunakan cara-cara yang suatu saat akan menghabiskan cadangan energinya sehingga terjadilah burnout.

Teori di atas menjelaskan secara tidak langsung bahwa saat karyawan mengalami burnout (kelelahan kerja) maka motivasi berprestasi dalam rangka optimalisasi produktivitas kerja dirinya akan mengalami penurunan.

Golembiewsky, dkk (1983) mengatakan bahwa akibat dari burnout dapat muncul dalam bentuk berkurangnya kepuasan kerja, memburuknya kinerja, dan produktivitas rendah. Apapun penyebabnya, munculnya burnout berakibat kerugian di pihak karyawan maupun organisasi.

Akibat burnout bagi organisasi menurut Jackson (dalam Jewell dan Siegall, 1998) adalah pemberian pelayanan yang berkualitas rendah bagi pelanggan (klien, pasien), merendahnya keterlibatan kerja pada bagian yang terkena dan meningkatnya orang yang pindah kerja. Orang-orang yang menderita burnout boleh jadi mencari peran administratif di mana mereka dapat berlindung pada pekerjaan diantara tumpukan surat-surat dan dokumen (Rosyid, 1996). Selain itu menurut Maslach dan Jackson (1981) burnout dapat menimbulkan kemerosotan kualitas ketelitian terhadap .tugas yang diberikan oleh staff.

Terdapat suatu kenyataan yang mengejutkan, bahwa penderita burn out adalah orang-orang yang bersemangat, energik, ambisius, dan memiliki prinsip yang kuat untuk tidak menjadi gagal dan merupakan figur pekerja keras (Freudenberger \& Richelson, dalam Feri Farhati \& Haryanto FR, 1996).

\section{KESIMPULAN}

Berdasarka $\mathrm{n}$ hasil analisa data yang telah dilakukan pada penelitian ini, dapat disimpulkan bahwa terdapat pengaruh antara self efficacy dan burnout terhadap produktifitas kerja. Secara simultan maupun secara parsial self efficacy dan burnout memiliki pengaruh yang signifikan 
terhadap produktifitas kerja karyawan PT Semen Indonesia.

Pengaruh self efficacy terhadap produktifitas kerja bernilai positif atau searah, yang berarti bahwa semakin besar self efficacy seorang karyawan maka semakin besar pula keyakinan akan kemampuan produktifitas kerjanya. Pengaruh burnout terhadap produktifitas kerja bernilai negatif, yang berarti bahwa semakin besar burnout seseorang karyawan maka semakin rendah produktifitas kerjanya. Selanjutnya, self efficacy dan burnout secara bersama-sama juga memiliki pengaruh yang signifikan terhadap produktifitas kerja karyawan PT Semen Indonesia.

\section{SARAN}

Berdasarkan hasil penelitian, peneliti ingin memberikan saran kepada beberapa pihak agar penelitian dapat memberikan manfaat kepada

\section{DAFTAR PUSTAKA}

Arikunto, S. 1998. Prosedur Penelitian (Satu Pendekatan Praktek) Edisi Revisi II. Jakarta: Rineka Cipta

Arnita. Nurjayanti. 2011. Hubungan antara self efficacy dengan produktivitas kerja pegawai batik. Tidak diterbitkan. Skripsi. Surakarta. Universitas Muhammadiyah Surakarta

Azwar, S. 2005. Sikap Manusia. Teori dan pengukurannya. Edisi ke-2. Yogyakarta: Pustaka Pelajar

Bandura, A. 1977. Self-efficacy: Toward a unifying theory of behavioral change. Psychological Review, 84, 191-215

Bandura, A. 1986. The explanatory and predictive scope of self-efficacy theory. Journal of Clinical and Social Psychology, 4, 359-373

Bandura, A. 1997. Self-efficacy and health behaviour. In A. Baum, S. Newman, J. Wienman, R. West, \& C. McManus (Eds.), Cambridge handbook of psychology, health and medicine (pp. 160-162). Cambridge: Cambridge University Press.

Caputo, J. S. 1991. Stress and Burnout in Library Service. Canada : The Oryx Press

Chasanah, Nur. 2008. Analisis Pengaruh Empowerment, Self efficacydan Budaya Organisasi terhadapKepuasan Kerja dalam Meningkatkan Kinerja Karyawan (Studi Empiris pada Karyawan PT. Mayora Tbk Regional Jateng dan DIY). Tesis Program Pasca Sarjana Magister Manajamen Universitas Diponegoro Semarang (tidak dipublikasikan) pihak-pihak yang berkesempatan menggunakan penelitian ini.

Saran untuk peneliti selanjutnya agar menyempurnakan beberapa bagian yang belum sempurna dalam penelitian ini, diantaranya pengambilan indikator dan penulisan aitem dari teori utama. Selain itu juga diperlukan teori yang sesuai dan mungkin bukan teori yang penulis gunakan.

Sedangkan saran untuk perusahaan agar pihak perusahaan mengetahui bahwa produktifitas kerja, burnout dan self efficacy merupakan hal pokok yang harus diperhatikan bagi karyawan, untuk itu diperlukan peran serta baik dari pihak perusahaan maupun pihak karyawan sendiri agar selalu melakukan evaluasi terhadap kinerja karyawan dan selalu memberikan masukan-masukan dan motivasi agar self efficacy karyawan semakin meningkat dan burnout karyawan semakin rendah.

Creswell, John W. 2010. Research Design Pendekatan Kualitatif, Kuantitatif, dan Mixed. Yogyakarta : Pustaka Pelajar

Dale Timple. 2011. Memotivasi Pegawai, Seri Manajemen Sumber Daya Manusia. Jakarta: Elex Media Komputindo

Engko, Cecilia. 2006. Pengaruh Kepuasan Kerja Terhadap Kinerja Individual Dengan Self Esteem dan Self efficacy Sebagai Variabel Intervening, Vol.10 No.1, hal 1-12

Farber, B. A. 1991. Crisis in education; Stress management (7th.ed). New York : America.

Ferguson C. E., and J. P. Gould. 1975. Microeconomic Theory, $4^{\text {th }}$ Edition

Firdaus, H. 2005. Pengaruh Shift Kerja Terhadap Kejadian Stres Kerja Pada Tenaga Kerja di Bagian Produksi Pabrik Kelapa Sawit PTPN 4 Kebun Pabatu Tebing Tinggi Tahun 2005. Skripsi, FKM-USU. Medan

Frank, Robert H. 1997. Microeconomic Behavior, $3^{\text {th }}$ Edition, McGraw-Hill Comp

Furnham, Adrian. 2002. The Psychology of Behaviour at Work. Hove: Psychologist Press

Gehmeyr, Andreas, 2000. The Word Wide Web http:/ www.fmi.uni passu.de/worter klaerungen/ burnout.html, Worterklaerungen-Burnout

Greenberg, Jerald dan Robert A. Baron. 1999. Behaviour in Organizations, Understanding 
and Managing The Human Side of Work. Third Edition. Allin and Bacon. A Division of Schuster. Massachuscets

Hadi, S. 2002. Metodelogi Research. Yogyakarta: Andi Offset

Hasibuan, Malayu. 2005. Manajemen Sumber Daya Manusia Edisi Revisi. Jakarta : PT. Bumi Aksara.

Hawari, Dadang. 1997. Alquran IImu Kedokteran Jiwa dan Kesehatan Mental. Jakarta: Dana Bhakti Yasa

Judiari, Josina. 2003. Kumpulan Handout. Tidak Diterbitkan

Kusnendi. 2003. Ekonomi Sumber Daya Manusia. Jakarta: PPUT

Muchdarsyah Sinungan. 2005. Produktivitas: Apa Dan Bagaimana. Jakarta. Bumi Aksara.

Nazir. 1999. Metode Penelitian, Cetakan Ketiga, Jakarta, Ghalia Indonesia

Rosyid, H.F. 1996. Burnout: Penghambat Produktivitas yang Perlu Dicermati. Buletin Psikologi, IV (1): $19-24$

Sapariyah, Rina Ani.2011. Pengaruh Self Esteem, Self efficacy Dan Locus Of Control Terhadap Kinerja Karyawan Dalam Perspektif Balance Scorecard Pada Perum Pegadaian Boyolali. Vol.19 No.18. STIE AUB.
Schaufelli, B, Wilmar. 1996. Work and Stress : Burnout and reciprocity, toward a dual-level social exchange model. Vol 10, no 3: 225-237

Schaufelli, B, Wilmar. 2001. Professional Burnout: Recent Developments in Theory and research. Washington DC: Taylor \& Francis. 52:397422

Schultz, D., \& Schultz, S.E. 1994. Theories of Personality 5th Edition. California : Brooks/ Cole

Schunk, D. H. 1983. Ability versus effort attributional feedback: Differential effects on self-efficacy and achievement. Journal of Educational Psychology, 75, 848 -856

Sinungan, Anogara. 2000. Manajemen Sumber Daya Manusia. Jakarta: Bumi Aksara

The Liang Gie, 1981. Efisiensi Kerja Bagi Pembangunan Negara, Jakarta: PT. Gunung Agung

Wibowo. 2013. perilaku dalam Organisasi. Jakarta: PT Raja Grafindo persada

Yeti Indrawati. 2014. Pengaruh Self Esteem, Self efficacy Dan Kepuasan Kerja Terhadap Kinerja Karyawan. Tidak diterbitkan. Thesis. Universitas Sam Ratulangi

Zimmerman, Barry, J. 1989. A Social Cognitive View of Self-Regulated Academic Learning. Journal of Educational Psychology. Vol. 81, No. 3, 329-339. 